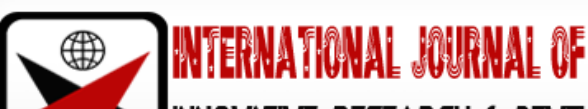

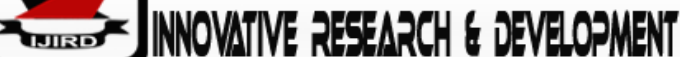

ISSN 2278-0211 (Online)

\section{Art as Language and Language as Art of Communication in a Digitally Evolving World}

\author{
Alimi Adesola Olutoyin \\ Senior Lecturer, Department of Design and Printing Technology, \\ Polytechnic Ibadan, Nigeria \\ Jayeoba Olatoyese Samson \\ Principal Lecturer, Department of General Studies, Polytechnic Ibadan, Nigeria
}

\begin{abstract}
:
Art is described as the expression of feelings in order to transmit an idea or evoke an emotion to a target audience. The evolution of art has reflected aesthetic and functional dimensions as well as offered innovative solutions to socioeconomic, political and cultural issues. Artistic and cultural iconography have been used across generations as communication codes to enable users of such codes exchange symbols to which they are most familiar. Language is a purely human and non-instinctive method of communicating ideas, notions and desires by means of a system of voluntarily produced symbols. Languages differ across races, colour and creed. Most languages evolved from culture and behavioural patterns of people. Given the ever-increasing technological impact on the present global space, communication has become transactional, affective, personal, instrumental and consummatory in the sense that the source and the receiver are constantly having an impact on each other through symbolic behaviour (Burgoon and Ruffner 1978). This paper, therefore intends to examine how art and language could be a potent mode of communication at a time of dominant digital evolution. The paper is an explorative study from existing literatures as secondary research method. It will also evaluate content, form and context of cartooning, tattooing, photo imagery and the universally accepted codes and icons.
\end{abstract}

Keywords: Art, language, communication, digital evolution

\section{Introduction}

Language is central to our discussion in this paper. Language is a vehicle for transmission of social and technical convections within the framework of cultural and linguistic possibilities. To the sociologists, language is a means of interaction, while the linguists opine that language is a systematic body of rules or rather, a system of arbitrary symbols used in the process of communication (Jayeoba 2016). Among the uses of language identified by scholars include: Language, as a means of communication, a vehicle for the transmission of culture, a tool for phatic communion(greetings), as an instrument of action, as a vehicle of thought, meta-linguistic functions, just to mention but a few.

Communication is an essential part of human interaction. Hannerman and Williams (1975) posit that communication is a means of facilitating social interaction and cohesion in a given society. This is why Michael and Michael (1978) see communication as transactional because all interactive signals in a communication framework impact on the sender and receiver automatically and simultaneously. Ayodele and Jayeoba (2019) define communication as transmission of a message, an idea, a thought, a code, an attitude or feeling from one person, known as sender or encoder, to another, known as receiver or decoder through the use of agreed symbol(s) in such a way that the idea or message is received, acted upon and a feedback is given. Symbolic communication, according to Alimi (2016) is the use of a system of customised artistic symbols whose definition, interpretation and usage are agreed upon by the community of users. While symbols generally are signifiers of specific meanings that are associated to lifestyle and experiences of users, its communicative potentials make it a potent language form that can be transferred from one place to another. In recent history, uses of codes, icons and signs that cut across cultures and creed have increased and became more popular because of social media platforms that have connected people to engage in mutual conversations on developmental or entertainment issues. Although, Nigeria is a society of diversity of cultures, yet most of the cultures share interfaces of meanings by adopting popular signs and codes that enables their communication to be seamless and effective. Use of tattoos, laali, tiroo, tribal marks aside from body painting and mascot designs on fashion and celebrity models has affected values and beliefs in a veritable way to attract target recipients of such communication styles.

Notes are brief communication of important information in business and personal relationships. They may contain reminders, request or suggestions. Sometimes, they are left on small squares of paper for another member of the office or family to see. On the other hand, letters are longer than notes and may cover several topics. The topic of a letter could be a solicitation, complaint, offer or request. A letter can be informative or inspirational, business or personal. 
Personal letters usually are written from one person to another person or group. Letters of famous or influential people often become important historical, political or religious documents.

Meanwhile, electronic communication could be an email which is a kind of note or letter that is sent electronically through the internet. It is a speedy form of verbal communication that contains its own special set of rules. Using all capital letters can be interpreted as screaming as the person receiving the email, which can lead to misunderstanding and problems in the workplace. Text messaging or texting is another modern technological form of verbal communication. Spelling rules are often set aside allowing forms like ' $U$ ' instead of 'you and '2' instead of 'too' or 'to'. Text messages are very short and are communicated through cell phones and other mobile electronic devices. Today, e-language is the vogue, which is characterized with deviations of norms of formal writing.

On spoken communication, speeches are made by political candidates and other public figures to persuade an audience to adopt their points of views, ideologies or take particular courses of action. Speeches may be delivered with the use of notes, telephones, and power-point slides, thus mixing written and oral or verbal communication. Sermon is a type of speech that occurs in religious services. Religious leaders use sermons to instruct their congregation regarding their lives and social issues. They emphasize on doctrines and dogmas as stipulated by the tenets of their faith. They motivate their adherents or followers on the gains of their faith through diligent sermons. Spoken communication occurs most basically in any interpersonal conversation, whether face-to-face or over the telephone.

Nayab (2011) sees communication as imparting or interchanging thoughts, opinions or information among people by speech, writing or signs. People communicate in different ways with the three typical types, being verbal, non-verbal and visual. Verbal communication entails the use of words in delivering the intended message, e.g., lecturing. The two major forms of verbal communication include written and oral communication. Written communication includes traditional pen and paper letters and documents, typed electronic documents, e-mails, text charts, SMS and anything else conveyed through written symbols such as language. This type of communication is indispensable for formal business communication and issuing legal instructions. Communication forms that predominately use written communication include handbooks, brochures, contacts, memos, press releases, formal business proposals and the like. The effectiveness of written communication depends on the writing style, grammar, vocabulary and clarity.

Oral communication is another form of verbal communication, otherwise referred to as the spoken word, either face-to-face, or any other medium, i.e.: telephone conversation, while informal form of communication is unofficial, yet, very relevant in any system. Forms of informal communication include rumors and grapevine. Informal communication provides an alternative to formal communication and it is highly flexible. Various forms of informal communication and formal communications such as lectures, conferences are forms of oral communication. Oral communication finds its use in discussions and casual informal communications. The effectiveness of oral conversations depends on the clarity of speech, voice modulation, pitch, volume, speed and even non-verbal communications such as body language and visual cues.

Verbal communication makes the process of communication easier and faster, and remains the most employed form of communication. Yet this makes up only seven percent of all human communication. Non-Verbal Communication entails communicating by sending and receiving wordless messages, that is, communicating through other means than the use of words. It usually stands alone and conveys messages on its own. Physical non-verbal communication or body language includes facial expressions, eye contact, body posture, gestures such as a wave, pointed finger and the like, overall body movements, tone of voice, touch and other facial expressions are the most common among all non-verbal communication. For instance, a smile or a frown conveys distinct emotions hard to express through verbal codes. Research estimates that body language, including facial expressions, account for 55 percent of all communication (Wikimedia, 2011)

Para-language is the way something is said, rather than what is actually said, is an important component of nonverbal communication. It includes voice quality, intonation, pitch, stress, emotion, tone and style of speaking, and communicates approval, interest or the lack of them. Art and language have been a veritable means of communicating to people over time in the most effective way based on conventional symbols that have been agreed upon by their users.

\section{Literature Review}

The view of research as a global conversation demands that research be situated within existing studies that are related to its focus. In this paper, previous studies that are related to the study focus are reviewed. Theoretical and empirical literature is reviewed to locate where the conversation on the issues of art as language and language as art is, in order to find for the present research an entry point into the conversation.

In certain sub-cultures or among certain people groups, symbolic communication is essentially integrated into their social system. For instance, in Yoruba-land, the use of 'aroko' is a common phenomenon. Symbolic communication is also revealed in religion, and ego-building situations. In Christianity, the cross of Christ is revered as a sacred emblem (symbol) of the Christian faith while Islam is recognized by a crescent and a star.

Symbols, unlike icons and indexes, share no resemblance with the object in any way. This sign is governed by a rule or convention or agreement between or among the users. For instance, the Nigeria's Green and White coloured flag is a symbol of the Nigerian state. Pierce (2001) define symbol as a sign which refer to the object that it denotes by virtue of a law, usually general association to be interpreted as referring to that object. This implies that when we think, we already have a picture on our mind of our intentions in the form of signs.

Symbolic communication lends credence to the agreed conventions regarding certain rules and regulations. Globally, the codes of Road safety commissions have common features. This is because the convention guiding the uses of roads is universal in its operations and interpretation. For example, zebra crossing marks is an indication that vehicles should slow down at such points to allow pedestrians to cross the road. Aside road marks or symbols, there are other signs 
and symbols that show the way to a particular place where certain services are obtainable. Other uses of symbols that have the potential to communicate to passersby are Logos. Logos are representational of an organization's ideology or philosophy.

Alimi (2009) explained that signs come as an abbreviated mode of communicating a message to a large heterogeneous audience in a very simple but clear, detailed and unambiguous manner about the vision, mission and philosophies of an organization symbols also help to orientate the publics of a community on a number of civic responsibilities and issues relating to social life.

Most institutions, over the years, have adopted the use of logos within which they often build their corporate philosophies and mission. A logo sign can speak volumes about an organization in more ways than one. Logo signs usually bear the image representing an organization's policies and pursuits as well as bear the house colours of such a body. Some logos are designed with illustrative visuals using human figures basic shapes or animals or birds while others combine letters of the alphabet with colours.

Meanwhile, in a seeming departure from the above, Kosut (2015) examined tattooing as an ancient and contemporary form of body inscription and modification with scholarly juxtaposition of research in the behavioural sciences that links tattoos to deviant and antisocial behaviours, with ethnographic and social scientific studies that place tattoos within cultural, symbolic, aesthetic and prosocial frameworks.

In a similar study on tattoo iconography, Sanders (1989) highlighted the beneficial dimensions of tattooing as a veritable contemporary form of transmitting information as it has been used to print signs, symbols and other memorable visuals on human body. His work emphasised that beyond the functions of fashion and trendy lifestyles, tattoos tend to be indelible to keep memorials of tradition, religion, love, marriage, bereavement and other events but did not mention issues related to art as elements of communication.

Sanders (1989) gave an insight into how public event planners have adopted the use of tattoos aside from body paintings and mascot designs on willing models in order to showcase their products especially celebrity models. Although, the work revealed that getting a tattoo is a visceral and direct way to enact and announce a message to others, yet the work did not discuss art or language related iconography.

Morris (1980) cautions against defining semiotics as 'science' of signs since the study offer no universal theoretical assumption, model and empiricism. Rather, semiotics is the study of sign which is basically subjective but publicized and later conventionalized. Man, and everything in his environment are signs; thus, they are meaninggenerating potentials. Morris (1971) sees semantics as being interspersed with syntax, semantics and pragmatics in their respective reflection on language rules, language meaning as well as the context. Semiotics became a major theoretical approach to cultural studies in the late 60s partially as a result of the work of Barthes (1957) titled Mythologies. Saussure contrives semiotics to be primarily preoccupied with a signifier, which means the form through which a sign is expressed by the sign. He refers to signification as a concept that captures the relationship existing between the signifier and the signified.

Bathes (1961), in his opinion, says semiotics is paradoxical. He further employs Persian's conceptual scope of semiotics. He puts it as semiology aiming to take in any system of signs whatever their substance and limits, images, features, musical sounds objects and the complex association of all of these which form the content of ritual convention or public entertainment these constitute, if not language or least systems of signification but Wikimedia (2006) simply puts semiotics as a field concerned with how meaning is transmitted and understood. Kippers (2003) emphasize culture as the major factor in producing and interpreting signs.

To Pierce, semiotics is a social action or an influence which entails a triangular relationship among sign, its object and its interpretation. He further reiterates that a sign is any communicative code system; linguistic and non-linguistic. He gives three types of signs: icons, symbolic and indexes. Each typology passes through the trio-semiotic processes, the sign (form), the object and the interpretation. Icons is a type of sign which resembles its object in a way, sharing one or more features or character or properties of its object e.g., portraits, cartoons or models. In figures 1 and 2, social media icons are represented to signify different applications. An index is a type of sign, the relationship between the sign and its objects is not resemblance-based. Rather, an index shares a direct physical connection with its objects. For example, a clock is an index of time and money, an index of wealth. Indexes could be inferred or observed. Examples include: Natural signs: (smoke, echoes, footprints), Medical symptoms (pain, rash, pulse rate) indexes of diseases or ill health as well as Personal signature or indexes of an individual. In figures 3, 4, 5, 6 and 7, tattoo iconography was indicated to reflect some ways of communicating different ideologies and lifestyles. Figures 8, 9 and 10 are religious and cultural icons. This paper, however, intends to address the areas that have not been sufficiently covered by the works of the scholars whose works were reviewed in this study. 


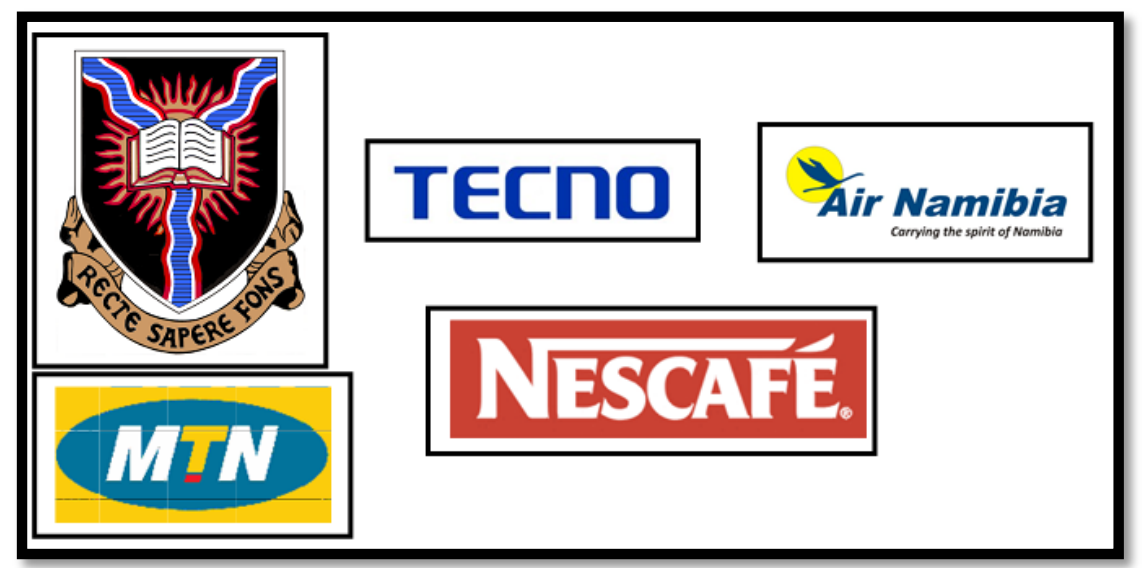

Figure 1: Some Challenging Logo Signs with Which Some Organizations Have Been Branded and Identified Over the Years

Symbols that are used to educate people within the social system on various issues like road safety, health matters or need to seek for help in matters of emergency include:

- Zebra crossing

- Children crossing

- No smoking

- Don't urinate here *Heavy truck here * slow down

- Eatery/restaurant here* swimming pool * stadium ahead

- $\quad$ Church * mosque* Red. Cross * no parking

- $\quad$ Recycle * urinary

\subsection{Aroko: A Symbol of Traditional Mode of Communication}

Aroko, the use of material objects packaged together in specific ways, was the traditional system of sending messages to people among the Yoruba people in the past. Against the ecological background of the Yoruba country, the choice of certain vegetational, animal or other resources in an area could be justified as man can only use the resources available to him. The elements of Aroko namely, the sender, the Aroko (materials/objects) and the receiver have to operate within an encompassing element, that is, the context to make an Aroko meaningful. There are three types of Aroko, the casual, the formal and the classified or highly coded Aroko are identified with illustrations of the various functions of Aroko in the Yoruba culture.

\subsection{Some Common Aroko Signs and Their Symbolic Interpretations in Yoruba Land Are Here Highlighted}

- Fish is sent to an individual to convey a meaning of negativity or ill-luck. It is a pointer to the fact that something is negative and inconsequential.

- Crab is a symbol of a good omen. It connotes hopefulness and positivism

- Gun powder is used to convey message of war and hostilities

- A matchbox full of matchsticks sent to the bride's parent is a way to show that a newly wedded lady is found by her husband to be a virgin while an empty matchbox is the reverse

- A white handkerchief with blood stain is sent to the father of the groom or bride by a proud and fulfilled groom to show that he was responsible for deflowering the bride.

- A dry leg of rabbit (ese ehoro) tied with raffia (iko) sent to a person indicate ejection of this person from a community. It implies that such a person is excommunicated or advised to leave the city as his safety may not be guaranteed henceforth.

- A basket that is already opened at the bottom (apere-ajadi) and a gourd (akeregbe) filled with palm wine halfway is also an indication that a woman is not met as a virgin

- A traditional cap (fila) can be sent to somebody indicating that the attention of that person is needed immediately.

- When a sponge and a local cream or cam-wood (osun) is sent to the parents of a bride after nine months of her wedding. It is an indication that their daughter has put to bed (delivered a baby)

\section{Conclusion}

It is no gainsaying that communication is advancing by the speed of light. Technology has changed the trend of things in very significant ways. From the colours, pictures, and typefaces on billboard arts, to the effects of photographs in newspapers and magazines: the unschooled populace are becoming aware of the goings-on in their environment.

From prehistoric days to the machine generation, visual communications have been quite impactful on the dealings and activities of man. However, as suggested in this paper, every form of communication is principally significant and geared towards eliciting responses from the targets to which it is directed. It is needful for government and stakeholders in the communication industry to boost the effort towards reactivating traditional mode of communication in order to sustain the legacies of the ancient past. 


\section{References}

i. Albers, Josef. Interaction of Colour, rev. ed. New Haven, CT: Yale University Press, 1975

ii. Althusser, Louis 'Ideology and Ideological state Apparatuses (Notes Towards an Investigation)' In Mapping Ideology: ed. Savoy Zizek pp 100 - 140 London and New York, 1994

iii. Alimi M.M. Communicating Through Cartoons A psycholinguistic study of the Language of Cartoons in Some Nigerian Newspaper: unpublished Ph. D. Thesis. University of ibadan 1986.

iv. Alimi A. O. Communication in Outdoor Advertising: Role and Prospects Symphony Journal of Arts and Aesthetics Vol. 4:54 - 672004

v. Alimi, A. O. (2009). Basic Principles of Graphics Design and Printing Technology, Ibadan, Crownix Media Concepts.

vi. Arntson Amy E. (2007) Graphic Design Basics, Fifth Ed Clark Baxter Wards worth, Boston, MA 02210-1202, USA

vii. Armstrong M. L., Strappy, D.J. Gabriel, D. C. and Anderson R. R. (1996) Motivation for Tattoo Removal Archives of Dermatology, 132 (4) 412 - 416

viii. Anderson R. R. Tattooing should be regulated New England Journal of Medicine $326-207$

ix. Ayodele M.O and Jayeoba O.S (2019) Dynamics of Organizational Communication. Precious Prints, Ibadan, Oyo State, Nigeria.

x. Barthes, R. (1983) Literary Theory and Connotations, Paris: the French Press,

xi. Berlin, B and Kay P. (1969) Basic Colour Terms: Their Universality and Evolution, Berkeley: University of California Press

xii. Birren, Faber. Ostwald: (1969) The Color Primer. New York: van Nostrand Reinhold,

xiii. Boudieu Pierre 'Language and Symbolic Power' Trans Giro Raymond and Matthew Adamson, Cambridge

xiv. Bohren, F. Graig Fundamentals of Atmospheric Radiation: An Introduction with 400 problems

xv. Burgoon, M. and Ruffner, M. (1978). Human Communication: An Introduction. New Jersey: Holt, Rinehart and Winston Press.

xvi. Doris David T. 'Vigilant Things: The Strange Fates of ordinary objects in Southwestern Nigeria unpublished Ph. D. dissertation Yale University 2001.

xvii. Folarin, B. (1998). Theories of Mass Communication: An Introductory Text. Ibadan: 'Stirling-Horden Publishers.

xviii. Gerritsen, Frank J. (1974) Theory and Practice of colour. New York van Nostrand Reinhold, 1974

xix. Greif J. and Hewitt, W. The Living canvas: Health Issues in Tattooing, body piercing and branding, Advances for Nurse Practitioners 12(3) 26 - 31, 82, 1998

xx. Hardy C. Arthur and Perrin H. Fred. (1932) The Principles of Optics. McGraw - Hill Book Co. Inc., New York

xxi. Hanneman, J. G. and William, J.M. (1975). Communication and Behaviour, Philippines: Wesley Publishing Co. Inc

xxii. Hewitt, Walter and Greif, Judith (1996) Tattooing and Body Piercing Rutgers University of Health Service, Texas 1996

xxiii. Jayeoba O.S (2018) Dimensions of Venue Oriented Communication in Traditional African Society in Language and Literature for Communication in Human Societies, Africatex Media, Porto- Novo, Republic of Benin. (Pan African University Institute)

xxiv. Jayeoba O.S(2016) The Use of English for Tertiary Institution Students: ESL Perspective, Precious Print, Ibadan, Oyo State, Nigeria

xxv. Kippers, Harald. (1973) Colour: origin, systems, uses. New York: van Nostraid Reinhold

xxvi. Long, G.E. and Rickman, L. S. (1994) Infection and Complication of Tattoos. Clinical inflections Disease 18(4), 610-619

xxvii. Macbride, S; Abel, E and Omu F. I. A. Many voices, one world: communication and society, Today and Tomorrow Ibadan University press and Parris: The VNESCO Press.

xxviii. Michael B. and Michael R (1978) Communication Today MacDraw Hill NY

xxix. Myers, J. (1992).Nonmainstream Body Modification Journal of contemporary Ethnography, 21(3), 267 - 306 Saunders C. (1989).Customizing the body: The Art and culture of Tattooing,

xxx. Philadelphia: Temple University Press

xxxi. Zelanshi Paul, and Mary Pat Fisher (1989). Colour, Englewood Cliffs. NJ: Bentice- Hall 


\section{Appendix}

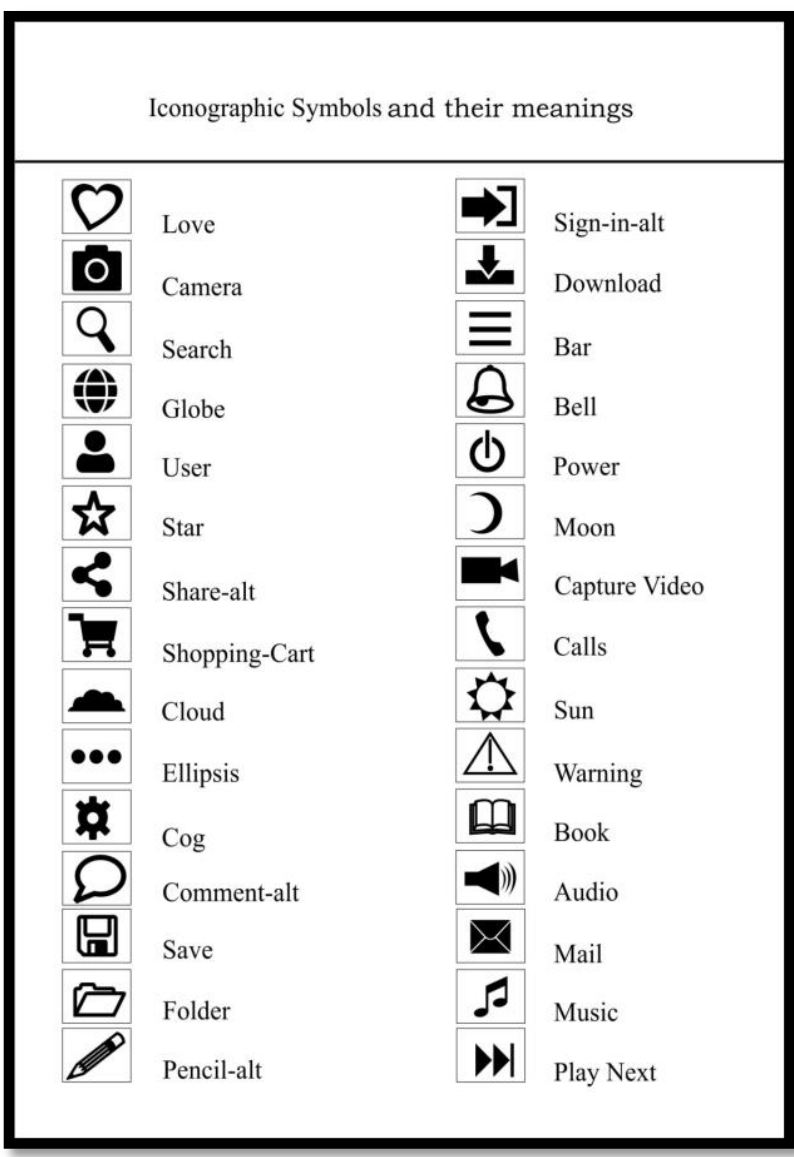

Figure 2: Iconographic Symbols and Their Meanings

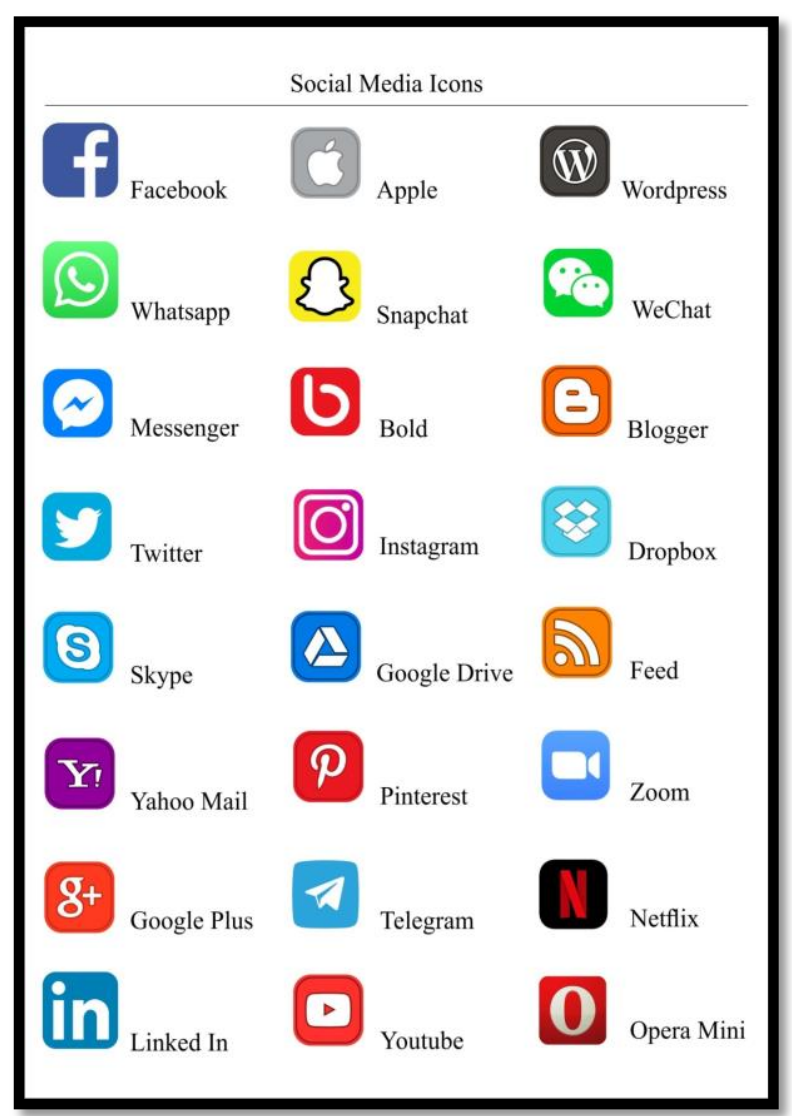

Figure 3: Social Media Icons 
Tattoo iconography made on human body with symbols communicating different meanings.

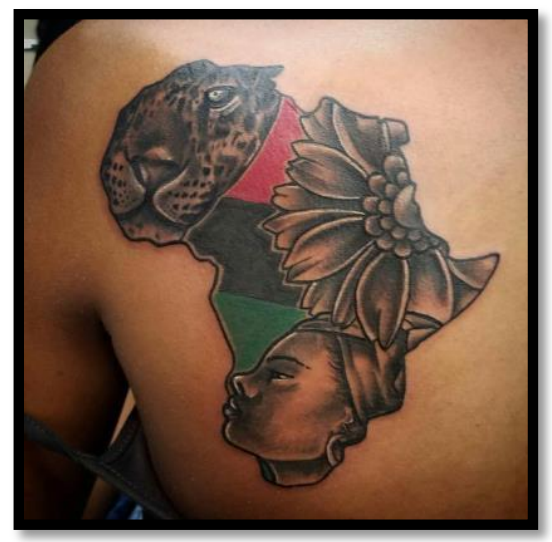

Figure 4: Tattoo Iconography on Human Body with the Use of African Motif

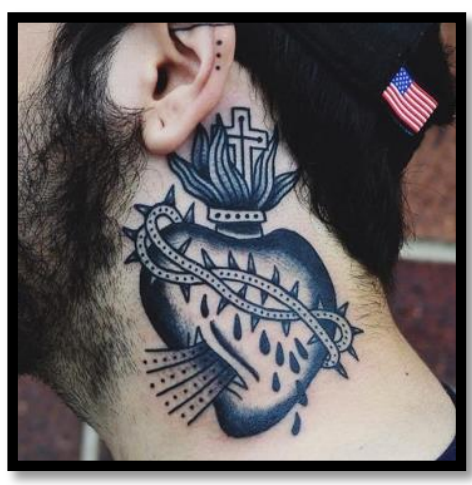

Figure 5: Tattoo Iconography on Human Body with the Motif of Crown of Thorns Around the Shape of Human Heart

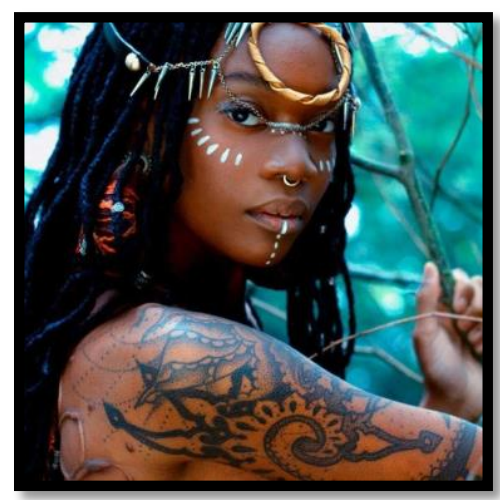

Figure 6: An African Lady with Tattoo Icons on Her Skin to Express Cultural Pride

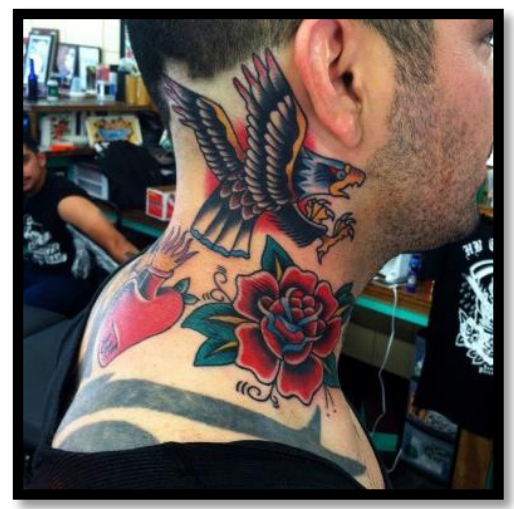

Figure 7: Image of Tattoo Icons with the Motif of an Eagle and Flowers on Human Skin 


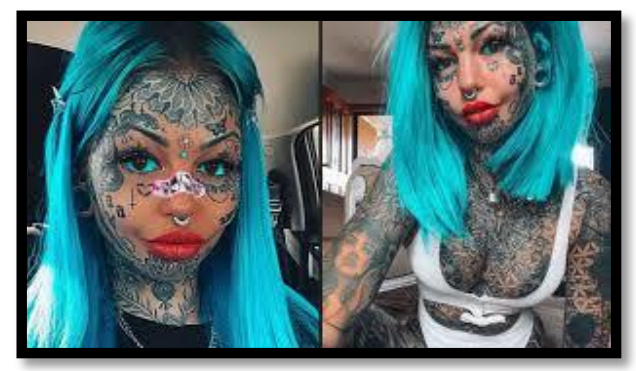

Figure 8: A Heavily Tattooed American Lady and Advertising Model With Varieties of Symbols And Motifs on Her Body

Religious Iconographic images

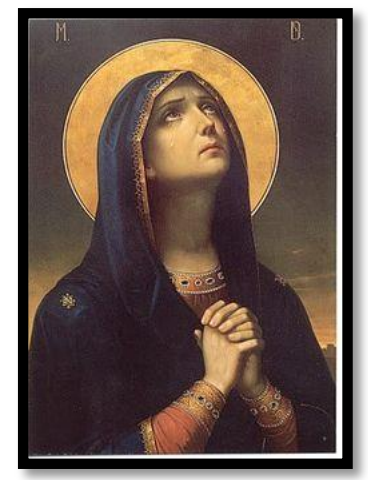

Figure 9: Christian Religious Iconography Shows

The Image of Mary The Mother of Jesus

With 'Halo' on Her Head Depicting Sainthood

Traditional Icons in Yoruba land

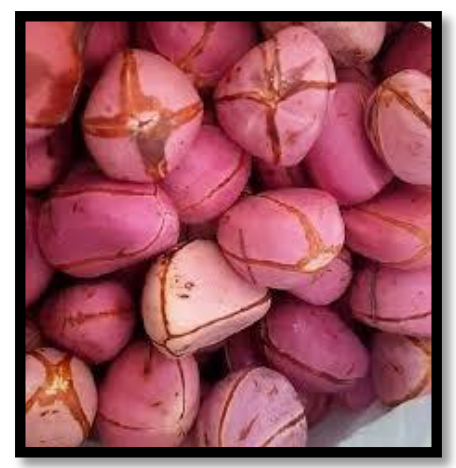

Figure 10: Image of Kolanut Fruit from the Indigenous

West Africa Is Used in Traditional Ceremonies

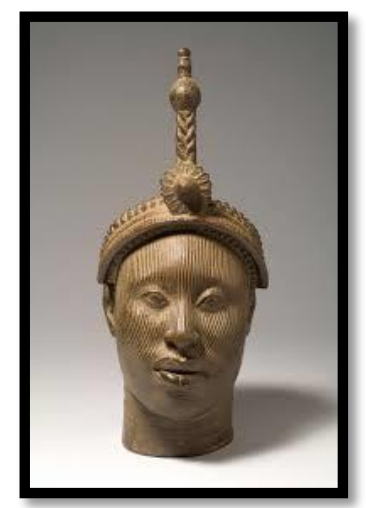

Figure 11: Iconographic Image of Ori Olokun

(The Bronze Head) Fron Ile Ife 